\section{Virus del sarampión: otro extranjero en la Copa del Mundo de la FIFA 2014}

\author{
Sr. Editor: \\ El sarampión es una enfermedad infecciosa, aguda \\ y exantemática, causada por un paramixovirus del \\ género Morbillivirus ${ }^{1}$. La enfermedad desde el punto \\ de vista clínico, presenta dos fases diferenciables: \\ prodrómica y exantemática o eruptiva. La primera \\ fase está caracterizada por fiebre elevada, tos, \\ rinorrea, conjuntivitis y de manera patogno- \\ mónica las manchas exantemáticas de Koplik. La \\ segunda se inicia con la aparición de manchas \\ rojas parduscas que aparecen en la cara y \\ posteriormente se generalizan².
}

Su transmisibilidad está dada principalmente a través de gotas respiratorias suspendidas en el aire, las cuales entran en contacto con las vías respiratorias superiores o la conjuntiva de individuos susceptibles. Esta transmisión es facilitada en los ambientes cerrados, con hacinamiento y difícil manejo higiénico, tales como escuelas, jardines, instituciones clínicas y hospitalarias ${ }^{3}$. Debido a esto, es considerada una de las viriasis más contagiosas del mundo $y$, por ende, un problema de salud pública.

Según la Organización Mundial de la Salud (OMS), en 2012 hubo 122000 muertes por Sarampión a nivel mundial; la mayoría de ellas en menores de 5 años ${ }^{4}$. Hacia este mismo año, diferentes instituciones elaboraron un Plan de Acción Global sobre Vacunas (GVAP), como plan estratégico mundial contra el Sarampión, planteando que para finales del año 2015, debería reducirse la mortalidad global de Sarampión por lo menos en un $95 \%$, comparado con estimaciones del año $2000^{4}$.

Ante esta evidencia, muchas iniciativas alrededor del mundo se gestaron; más de 180 países participaron en los programas de vacunación mundial destinados a proteger y mejorar la vida de los niños y madres en todo el mundo de forma rápida y sostenible, con tal de erradicar el sarampión.

Tradicionalmente, el sarampión en Colombia ha presentado un comportamiento endémico, con ocasionales brotes epidémicos, estos últimos, debido a casos importados provenientes de Venezuela, Brasil, Madrid y Berlín, en los años 2002, 2011, 2012 y 2013, respectivamente; en los cuales, las actividades de bloqueo epidemiológico, vigilancia y control del brote, verificación del estado inmune de familiares y la vacunación fueron efectivos. Es así como desde el año 2002 hasta la fecha, Colombia ha demostrado cero casos de sarampión autóctono, razón por la cual se publicó a principios del año en curso: "Colombia, primer país de América Latina libre de sarampión y rubéola"; declaración sugerida por un Comité Internacional de Expertos, tras un exhaustivo seguimiento epidemiológico ${ }^{5}$. En ese orden de ideas, Colombia es oficialmente hoy un país libre de esta enfermedad infecciosa, el primero en América Latina en alcanzar esta certificación.

La intensificación de las actividades de vacunación ha influido en forma decisiva en la reducción de las muertes por sarampión en todo el mundo, por lo que se debe sostener de manera masiva la cobertura de inmunización contra el sarampión en $95 \%$ o más, mantener la vigilancia estandarizada con alta calidad y garantizar una respuesta oportuna y eficaz a los brotes, además de llevar a cabo actividades de investigación y desarrollo necesarias para respaldar medidas costo efectivas y mejorar la vacunación y los instrumentos diagnósticos (Resolución CSP28.R14). Todo esto, con el fin de alcanzar los objetivos mundiales para 2015 y 2020.

Los países latinoamericanos no están exentos de los casos foráneos de sarampión y ante la culminada Copa Mundial de la FIFA que se llevó a cabo en doce ciudades de Brasil (el país más grande de América del Sur) entre el 12 de junio y el 13 de julio de 2014, en donde un gran número de viajeros nacionales e internacionales se dieron cita en dicho país, existe un riesgo inminente de importación de enfermedades transmisibles a regiones vecinas, específicamente, de reintroducción de la transmisión del virus de sarampión. De hecho, con anticipación y como preparación para el incremento de los viajeros, desde y hacia Brasil, un panel de expertos de la región, de la Sociedad Latinoamericana de Medicina del Viajero (SLAMVI) desarrollaron las recomendaciones para evitar el riesgo de la adquisición de enfermedades transmisibles en los principales destinos, las vacunas recomendadas y otras medidas específicas (http://www.slamviweb.org/es/home/Muncial\%20 de $\% 20$ Futbol $\% 20$ Consejos $\% 20$ para $\% 20$ 
Viajeros\%20SLAMVI.pdf) ${ }^{7}$. Dicho documento recopila las estrategias preventivas para reducir el riesgo de contraer enfermedades producidas por vectores (Malaria, Fiebre Chikunguya y Dengue); enfermedades transmitidas por los alimentos (Hepatitis A, Fiebre tifoidea, Giardiasis y la Diarrea del viajero); enfermedades de transmisión sexual (ETS) y enfermedades inmunoprevenibles (Fiebre amarilla y Sarampión). entre otras.

A pesar de la interrupción de la circulación del virus del sarampión en Brasil hacia el año 2000, se han producido brotes de la enfermedad desde el año pasado en las ciudades de Fortaleza, Recife, Sao Paulo, Belo Horizonte, Curitiba y Brasilia ${ }^{7}$; lugares que fueron sedes de la concluida Copa Mundial de la FIFA 2014. En general, los riesgos a los que están enfrentados quienes visitaron el país vecino son altos, los viajeros debieron estar preparados para todo tipo de desafíos ${ }^{8}$; en especial, debieron precisar con el certificado de la vacuna como herramienta preventiva al menos 15 días antes del viaje a la Copa Mundial de Fútbol 2014. Mientras tanto, los clínicos y los actores de vigilancia en salud pública colombiana deben mantenerse al día con los informes de brotes, identificar oportunamente casos sospechosos y responder rápidamente a los viajeros con infecciones para prevenir la propagación del Sarampión después de la importación ${ }^{9}$.

En conclusión, la eliminación del sarampión exige la participación activa de toda la población; una comunidad debidamente informada sobre el sarampión permite el logro de coberturas de vacunación altas y garantiza el éxito de las campañas dirigidas a la erradicación de la enfermedad. No se trata de simplemente afirmar que el territorio nacional está libre del virus, sino de sumar fuerzas con la participación activa de los países fronterizos en la coordinación de estrategias eficaces de control epidemiológico que conduzcan a una certificación real y contundente no solo en el territorio nacional, sino en toda la región de América.

\section{BIBLIOGRAFÍA}

1. Latorre $\mathrm{N}$, Blanes $\mathrm{M}$. El sarampión como enfermedad reemergente. Actas Dermosifiliogr. 2013;104:533-4.

2. Benenson A. Benenson, Abram S. Manual para el control de enfermedades transmisibles. Decimosexta edición. Publicación Científica No 564. Washington, DC.:OPS/ OMS;1997.

3. Organización Panamericana de la Salud. La Erradicación del Sarampión: Guía Práctica. Washington DC: OPS, 1999: 28 (Cuaderno Técnico 41).

4. Organización Mundial de la Salud. Sarampión. Nota descriptiva $\mathrm{N}^{\circ} 286$ [internet]. Febrero de 2014 [consultado el 29-05-2014]. Disponible en: http://who.int/mediacentre/ factsheets/fs286/es/

5. Colombia, primer país de América Latina libre de sarampión y rubeóla. El Tiempo. 22 de Enero de 2014; Sec Salud (col. 1).

6. Resolución CSP28.R14 -Plan de acción para mantener la eliminación del sarampión, la rubéola y el síndrome de rubéola congénita en la Región de las Américas. 28 Conferencia Sanitaria Panamericana, 64 Sesión del Comité Regional; 20 de Septiembre de 2012; Washington,D.C.2012. p. 5.

7. Gallego V, Berberian G, Lloveras S, Verbanaz S, Chaves TS, Orduna T, Rodriguez-Morales AJ. The 2014 FIFA World Cup: communicable disease risks and advice for visitors to Brazil--a review from the Latin American Society for Travel Medicine (SLAMVI). Travel Med Infect Dis. 2014;12(3):20818.

8. Wilson ME, Chen LH. Health risks among travelers to Brazil: implications for the 2014 FIFA World Cup and 2016 Olympic Games. Travel Med Infect Dis. 2014;12(3):205-7.

9. Wilson ME, Chen LH, Han PV, Keystone JS, Cramer JP, Segurado A, et al. Illness in Travelers Returned From Brazil: The GeoSentinel Experience and Implications for the 2014 FIFA World Cup and the 2016 Summer Olympics. Clin Infect Dis. 2014;58(10):1347-1356.

\section{Bárbara Arroyo Salgadoa, Verónica Gómez Arcilab $^{\mathrm{b}}$, Yaleyvis Buelvas Montes ${ }^{\mathrm{c}}$, Andrea Salazar Trujillo ${ }^{d}$.}

a Bacterióloga. Magíster en Microbiología. Directora del Grupo GIMUC. ${ }^{b}$ Odontóloga. Facultad de Medicina. c Bióloga. Magíster en Microbiología. Facultad de Ciencias Exactas y Naturales.

d Estudiante de Medicina. Facultad de Medicina. GIMUC. Grupo de Investigaciones Microbiológicas de la Universidad de Cartagena (Colombia).

Correo electrónico: barroyos@unicartagena.edu.co vgomeza@unicartagena.edu.co 